\title{
HIV-related knowledge and AIDS stigma among college students in Yemen
}

A.M. Badahdah ${ }^{7}$ and N. Sayem ${ }^{2}$



ABSTRACT The present study analysed data from 501 Yemeni university students to examine their knowledge about HIV and their attitudes towards people with HIV/AIDS. The findings indicate that participants had several serious misunderstandings about HIV/AIDS and held negative attitudes toward people living with HIV/ AIDS. Although female students were less knowledgeable about HIV/AIDS than were male students, they held more positive attitudes toward people with HIV/AIDS. An overwhelming number of students expressed their willingness to get tested for HIV and recognized that AIDS is a serious issue facing their country. The study provides suggestions for HIV prevention efforts and ideas for future studies in Yemen.

Connaissances en termes de VIH et stigmatisation associée au sida chez des étudiants en République du Yémen

RÉSUMÉ La présente étude a analysé des informations recueillies auprès de 501 étudiants yéménites afin d'évaluer leurs connaissances sur le VIH et leur attitude vis-à-vis des personnes atteintes du VIH/sida. Les résultats montrent que les répondants présentaient de graves lacunes en termes de connaissances du VIH/sida et qu'ils réagissaient de manière négative envers les personnes infectées. Si les étudiantes étaient moins bien informées que les étudiants, elles adoptaient toutefois une attitude plus positive envers les personnes atteintes du VIH/sida. Un nombre considérable d'étudiants a exprimé le désir de bénéficier d'un test de dépistage du VIH et a admis que le sida représentait un grave problème auquel leur pays devait faire face. L'étude présente des propositions relatives aux efforts de prévention du VIH et des idées pour de futures études à réaliser en République du Yémen. 


\section{Introduction}

HIV/AIDS prevention strategies aspire to reduce HIV infection by changing the perceptions and behaviours that increase the likelihood of people becoming infected and altering the underlying structural arrangements that shape or constrain people's behaviours, such as poverty and gender inequality $[1]$. One of the structural factors that has been the target of HIV prevention efforts is stigma [2-4]. Since the beginning of the AIDS epidemic, AIDS-related stigma has been globally acknowledged as detrimental to the well-being of people living with HIV/AIDS (PLWHA) and a significant obstacle to HIV prevention programmes [2]. Stigma interferes with individuals' desire to seek treatment, disclose their health status, adhere to antiretroviral therapy or seek support. Some countries have made progress towards understanding AIDS-related stigma, its prevalence and its impact on the lives of PLWHA and their significant others. The few studies available on HIV/AIDS in countries of the Arab world, however, show the existence of various misconceptions about HIV/ AIDS and the pervasiveness of the stigmatization of individuals with HIV/ AIDS [5-7].

Although HIV/AIDS prevalence rates in the Eastern Mediterranean Region are low, the Region has one of the fastest-growing HIV infection rates in the world [8]. Djibouti and Sudan have the highest prevalence rates in the Arab world and are facing a generalized epidemic. Other countries, such as Morocco and the Libyan Arab Jamahiriya, are experiencing a localized epidemic. The main route of infection in the Arab world is unprotected heterosexual intercourse. However, in some countries injecting drugs is the major cause of HIV infection.

Although considerable success has been achieved in slowing the spread of AIDS, HIV rates continue to increase rapidly in some countries, including
Yemen. Yemen is a conservative and tribal state of 23 million people with a median age of 16.7 years and high rates of illiteracy, poverty and unemployment; it is one of the poorest and least-developed countries in the Arab world [9]. The World Health Organization (WHO) has estimated that there are approximately $24000 \mathrm{HIV}$-infected individuals in Yemen [10]. During the 1990s the majority of the infected people in Yemen were men; in 1995 for every 4 HIV-infected men there was 1 HIV-infected woman. However, the risk of HIV infection among Yemeni women has increased and in 2005 it was reported that as many women as men were infected [9].

Yemen lacks the basic tools to halt the spread of HIV. To illustrate this, only 107 patients are receiving antiretroviral therapy [11], and testing and counselling facilities are limited [12]. With this in mind, we were able to locate only 2 published empirical studies about HIV/AIDS in Yemen, one that examined individuals' knowledge and perceptions of individuals with HIV/ AIDS [13] and another that assessed Yemenis' attitudes toward the use of condoms as a means of HIV prevention [14]. The purpose of the present paper was to assess Yemeni students' knowledge of HIV/AIDS and the stigmatization of PLWHA. This is the first study to focus exclusively on young Yemenis, who represent $21.4 \%$ of the country's population [15].

\section{Methods}

\section{Sample}

To determine the sample size for the study, the proportion of students who held positive attitudes toward PLWHA and had accurate knowledge about HIV/AIDS was assumed to be $50 \%$. The sample size was estimated to be around 400 students. To minimize problems associated with unusable questionnaires we increased the sample size by $25 \%$. A convenience sample was selected consisting of 501 undergraduate students who attended a large public university in Sana'a, the capital of Yemen. Unintentionally, the sample size was divided almost equally between men and women (251 males and 250 females).

\section{Data collection}

The data were collected via a questionnaire that was distributed to students in psychology classes. The items for this study were selected from previous studies conducted by the first author in several countries in the Arab world [5] and from a study conducted in Yemen to develop an AIDS-related stigma scale [16]. The questionnaire contained several items about HIV/AIDS knowledge, AIDS-related stigma and other items related to HIV prevention.

For the knowledge index, 11 statements (e.g. "There is a cure for AIDS") were generated to assess students' general knowledge about HIV and its transmission. Students could choose from 3 options for each question: "correct", "wrong" and "don't know". The "don't know" answers were treated as wrong answers in the analysis. An index of AIDS knowledge was created that ranged from 0 to 11 , with higher scores indicating greater knowledge of HIV.

AIDS-related stigma was measured by 11 items that indicated the beliefs (e.g. "AIDS is a punishment from God"), emotional responses (e.g. "People with AIDS make me angry") and behavioural reactions towards PLWHA (e.g. "People with AIDS should be fired from jobs"). Participants responded to each statement on a Likert-type scale with possible responses ranging from 1 (very strongly agree) to 6 (very strongly disagree). Cronbach alpha was used to assess the internal consistency of the items of the AIDS stigma measure. The coefficient of reliability indicated that the 11 items were highly consistent $(\alpha=0.81)$.

Students were also asked about their willingness to take an HIV test 
and whether they knew someone with AIDS. To understand students' perceptions of the AIDS situation in Yemen, we asked them if they thought that HIV was an issue in Yemen and whether the media had exaggerated its prevalence.

\section{Data analysis}

SPSS, version 17 was used to analyse the data for this study. The mean and standard deviation (SD) were used as well as Student $t$-test, Spearman correlation and Cronbach alpha to assess the reliability of the stigma scale. The level of significance was $P<0.05$.

\section{Results}

The students' ages ranged from 17 to 29 years, mean 22 (SD 2.22) years, and the majority $(83.8 \%)$ were single. An overwhelming proportion of the participants (82.6\%) reported that they had grown up in a middle-income family

The mean score of students' knowledge about HIV transmission on the 11-item index was 6.70 (SD 1.87) (Table 1). Four out of 11 items were answered incorrectly by half or more of the students. Specifically, $69.2 \%$ of the participants either did not know or thought that there was a cure for AIDS and 51.8\% either did not know or believed that mothers cannot transmit HIV through breastfeeding. Only a fraction of the participants (28.9\%) knew that mosquito bites cannot transmit HIV.A third of the students (36.3\%) knew that condoms are effective in preventing sexually transmitted diseases such as HIV. Only a fewstudents (8.2\%) knew that they could not identify a person with AIDS by looking at him/ her, and 33.9\% lacked knowledge or provided the wrong answer when asked whether the HIV virus infects only homosexuals. Female students were less knowledgeable about HIV [mean score 6.50 (SD 1.85)] than were male students [mean score 6.90 (SD 1.87)]. This gender difference was statistically significant $(t=2.40, P<0.05)$.

Yemeni students' perceptions of PLWHA were slightly below the midpoint of the scale [mean score 3.48 (SD 1.01)]. More than half the respondents (52.1\%) agreed that "people with AIDS should be ashamed of themselves" and $56.5 \%$ said they would be ashamed if one of their relatives got AIDS (Table 2). Similarly, $66.3 \%$ believed that it is shameful to have people with AIDS in Yemen. Other AIDS-related emotional statements that a large proportion of participants endorsed were about sympathy and anger: $48.5 \%$ agreed that they find it personally difficult to sympathize with people with AIDS, and 42.7\% expressed anger toward people with AIDS. Although $60.3 \%$ of the students agreed that "AIDS is a punishment from God", many also thought that individuals with AIDS were not responsible for their infection (63.1\%). Statements about isolating PLWHA by dismissing them from their jobs or quarantining them were endorsed by $39.9 \%$ and $39.7 \%$ of the students respectively.

Female students overall expressed more positive attitudes towards PLWHA than did male students [mean score 3.82 (SD 0.90) versus 3.14 (SD 0.99)] $(t=7.87, P<0.001)$ (Table 2$)$. Students who had greater knowledge about HIV/AIDS also had higher attitude scores towards PLWHA than students who had some misconceptions about $\operatorname{HIV}(r=0.11, P<0.05)$.

Just over $85 \%$ of the participants indicated their willingness to take an HIV test. Thesestudents expressed more positive attitudes toward PLWHA than those who were not interested in taking the test [score 3.55 (SD 1.00) versus $3.25(\mathrm{SD} 1.10)](t=2.36, P<0.05)$. Twenty (20) students (4.0\%) reported knowing someone with HIV/AIDS. The majority of the students agreed that HIV is a problem facing their country (84.3\%) and that the issue is accurately presented in the media $(77.6 \%)$.

\begin{tabular}{|c|c|c|c|c|}
\hline \multirow[t]{2}{*}{ AIDS-related knowledge item } & \multicolumn{2}{|c|}{ Correct response } & \multicolumn{2}{|c|}{ Incorrect response $\mathrm{a}^{\mathrm{a}}$} \\
\hline & No. & $\%$ & No. & $\%$ \\
\hline Can tell if someone has AIDS by looking at him/her & 41 & 8.2 & $286^{\mathrm{b}}$ & 57.1 \\
\hline Only homosexuals get AIDS & 75 & 15.0 & $331^{\mathrm{b}}$ & 66.1 \\
\hline HIV lives in human body for years without symptoms & $383^{b}$ & 76.4 & 52 & 10.4 \\
\hline There is a cure for AIDS & 149 & 29.7 & $154^{\mathrm{b}}$ & 30.7 \\
\hline Pregnant women can transmit HIV to their unborn babies & $426^{\mathrm{b}}$ & 85.0 & 19 & 3.8 \\
\hline Can get HIV by touching someone with AIDS & 59 & 11.8 & $392^{\mathrm{b}}$ & 78.2 \\
\hline Can get HIV by using public phone & 17 & 3.4 & $407^{b}$ & 81.2 \\
\hline HIV can be transmitted through breastfeeding & $241^{b}$ & 48.1 & 94 & 18.8 \\
\hline Mosquito bites can transmit AIDS & 183 & 36.5 & $145^{\mathrm{b}}$ & 28.9 \\
\hline Condoms reduce the probability of getting HIV & $182^{\mathrm{b}}$ & 36.3 & 78 & 15.6 \\
\hline AIDS virus can be found in semen & $410^{\mathrm{b}}$ & 81.8 & 12 & 2.4 \\
\hline
\end{tabular}

${ }^{a}$ Don't know responses are not shown; ${ }^{b}$ Indicates the expected answer. 


\begin{tabular}{|c|c|c|c|c|c|c|}
\hline \multirow[t]{2}{*}{ Attitude item } & \multicolumn{2}{|c|}{$\begin{array}{c}\text { Males } \\
(n=251)\end{array}$} & \multicolumn{2}{|c|}{$\begin{array}{l}\text { Females } \\
(n=250)\end{array}$} & \multirow[t]{2}{*}{$t$-value } & \multirow[t]{2}{*}{$P$-value } \\
\hline & Mean score $^{\mathrm{a}}$ & SD & Mean score ${ }^{a}$ & SD & & \\
\hline People with AIDS should be fired from their jobs & 3.21 & 1.91 & 4.14 & 1.62 & 5.87 & $<0.05$ \\
\hline It is difficult to sympathize with people with AIDS & 3.29 & 1.62 & 3.86 & 1.52 & 3.99 & $<0.05$ \\
\hline I would be ashamed if a relative of mine got AIDS & 2.96 & 1.75 & 3.41 & 1.76 & 2.87 & $<0.05$ \\
\hline People with AIDS should be quarantined & 3.21 & 1.88 & 4.25 & 1.63 & 6.61 & $<0.05$ \\
\hline $\begin{array}{l}\text { If a friend of mine got HIV I would continue being friends } \\
\text { with him/her }\end{array}$ & 3.69 & 1.69 & 4.08 & 1.56 & 2.74 & $<0.05$ \\
\hline People with AIDS make me angry & 3.33 & 1.70 & 3.93 & 1.61 & 4.01 & $<0.05$ \\
\hline People with AIDS should be ashamed of themselves & 2.96 & 1.66 & 3.70 & 1.74 & 4.80 & $<0.05$ \\
\hline It does not bother me if my classmate has AIDS & 3.27 & 1.63 & 4.01 & 1.49 & 5.32 & $<0.05$ \\
\hline People with AIDS are responsible for getting AIDS & 3.54 & 1.85 & 4.30 & 1.69 & 4.80 & $<0.05$ \\
\hline It is shameful to have people with AIDS in Yemen & 2.57 & 1.63 & 3.00 & 1.76 & 2.88 & $<0.05$ \\
\hline AIDS is a punishment from God & 2.61 & 1.72 & 3.34 & 1.74 & 4.70 & $<0.05$ \\
\hline
\end{tabular}

${ }^{a}$ Higher scores $=$ more positive attitudes.

$S D=$ standard deviation.

\section{Discussion}

This study examined the misconceptions about HIV and the stigmatization of PLWHA in Yemen, a country that to date has been largely outside the realm of AIDS research. We found specific deficiencies in Yemeni students' knowledge about HIV. Most students erroneously believed that HIV cannot be transmitted via breastfeeding, that mosquito bites can infect people with HIV, that condom use is ineffective in preventing HIV infection and that there is a cure for AIDS. Al-Serouri et al. noted similar findings in their study in Yemen: $86 \%$ of the participants agreed that one can get infected with the AIDS virus from mosquito bites [13]. This misconception is probably due to the high prevalence of malaria in Yemen. According to the $\mathrm{WHO}$ "approximately $60 \%$ of the population live in areas with malaria transmission" [17].

Two knowledge items deserve close examination because of the significant role they play in HIV prevention. The first is about the effectiveness of condom use in preventing HIV infection. Only $36.3 \%$ of the participants were well informed about the role of condoms in reducing the probability of HIV infection.
Unfortunately, this figure is lower than that of Busulwa et al., who found in a household survey that $46 \%$ of Yemenis knew that condoms protect against sexually transmitted infections [14]. This lack of knowledge among young college students is disturbing because they are at a stage in their lives where they may be tempted to experiment with extramarital sex and drugs. One explanation for this deficiency in our sample, which we did not test directly, may be that our college students do not consider themselves at risk of acquiring HIV; hence knowledge about condoms is irrelevant. Although they acknowledge the seriousness of AIDS in Yemen, they might believe that AIDS is an issue among older adults or promiscuous individuals.

Another interpretation, which we believe is also applicable to the findings of Busulwa et al., is that most public health establishments in the Arab world do not advocate the use of condoms as a preventive measure in the fight against AIDS in their educational and prevention programmes [14]. This attitude is motivated by the misconception that promoting condom use is against the teaching of Islam and would encourage people to engage in unlawful sex [18]. This attitude was illustrated by a female college student who stated, "No, we should not encourage the use of condom [s] or the spread of condom[s] because this can cause the spread of diseases and other dangerous behaviour. No, it is forbidden. It is not allowed." [14].

The other knowledge item was about the availability of a cure for AIDS. Al Serouri et al. reported that $17 \%$ of the participants in their study in Yemen assumed that there was a cure for AIDS [13]. Unexpectedly, in our study a larger percentage of students were either unsure $(39.5 \%)$ or thought that a treatment did exist (29.7\%). Perhaps the students were not educated enough about HIV to be able to distinguish between antiretroviral therapy and a cure for AIDS. Another possible source of confusion is the claim made by Abdul Majeed Al-Zandani, a well-known Yemeni religious figure, who said he can cure people with AIDS. Such a false claim being publicized by a figure well-known in the country is dangerous to the public health of Yemenis, and trivializes HIV prevention efforts in Yemen.

Another important finding of this study is the gender gap in HIV knowledge, with Yemeni males being more knowledgeable about HIV/AIDS than 
their female counterparts. Although a gender gap was noted in other studies in Yemen [13] and the United Arab Emirates [19], our study pointed to 2 serious misconceptions that Yemeni female college students had about AIDS. We found that more males (43.0\%) than females $(29.6 \%)$ knew that condoms are effective in reducing the likelihood of HIV infection. Also more males (88.8\%) than females (74.8\%) knew that HIV can be transmitted through semen. This gap is grave and needs urgent attention from public health officials in Yemen because the limited data that exist suggest that the majority of HIVpositive Arab women have contracted it from their husbands [20].

Yemeni students' overall perception of PLWHA was not encouraging. The results suggest that students were divided equally in their emotional reactions and negative beliefs about PLWHA. At the behavioural level, around $40 \%$ of the students endorsed 2 statements about the need to socially isolate PLWHA. This tendency may be motivated by the students' perception that AIDS is a punishment from God. Studies from around the world and the
Eastern Mediterranean Region have found similar attitudes [21-24]. For example, $23.2 \%$ of those between the ages of 11 and 83 years from Eskisehir, Turkey [22], 14\% of those living in Tehran, Islamic Republic of Iran [23] and $28 \%$ of high-school students in Tunisia [24] supported such a statement.

One of most encouraging results of this study was the finding that correct knowledge about HIV/AIDS was associated with holding a positive image of PLWHA. Another one was that most students were willing to get tested for HIV, although such a desire may not be fulfilled because of the lack of resources in Yemen. Students' awareness of the magnitude of the AIDS problem in their country is a positive step that would facilitate HIV prevention efforts in Yemen. Health care professionals and nongovernmental organizations in Yemen should capitalize on these positive orientations and try to provide testing and counselling for young Yemenis. Only $4.0 \%$ of tudents reported that they knew someone with AIDS. This is less than the number reported by a sample of rural and urban residents in Yemen in which $15 \%$ of the 1400 participants said they knew someone with AIDS [25].

Despite the valuable contribution of this study, several limitations should be mentioned. The findings cannot be generalized to all college students in Yemen because the sample was conveniently collected from 1 university in 1 city. Furthermore, because no standardized AIDS-stigma scale has been developed exclusively for Yemenis or Arabs in general, we used a collection of items that the first author had used in previous studies. At this juncture, we believe that there is a need to construct an AIDS stigma scale that is appropriate to the Arab culture.

\section{Conclusion}

Our findings demonstrate the benefit of furnishing Yemeni students with accurate information about HIV/AIDS as a strategy to eliminate the stigma of AIDS. Educational campaigns in Yemen need to present AIDS as a health issue rather than a moral failure and find a way to incorporate condom use into HIV prevention efforts.

\section{References}

1. Coates TJ, Richter L, Caceres C. Behavioural strategies to reduce HIV transmission: how to make them work better. Lancet, 2008, 372:669-684.

2. Heijnders M, Van Der Meij S. The fight against stigma: an overview of the stigma-reduction strategies and interventions. Psychology, Health and Medicine, 2006, 11:353-363.

3. Goffman E. Stigma: notes on the management of a spoiled identity. Englewoods Cliffs, New Jersey, Spectrum, 1963,

4. Link B, Phelan JC. Conceptualizing stigma. Annual Review of Sociology, 2001, 27:363-385.

5. Badahdah AM. Saudi attitudes toward people with HIV/AIDS. International Journal of STD and AIDS, 2005, 16:837-838.

6. Musso S, Fanget D, Cherabi K. Religion and education for HIV/ AIDS prevention: an Arab-Islamic view. Prospective, 2002, 32:207-213.

7. Roudi-Fahimi F. Time to intervene: preventing the spread of HIV/ AIDS in the Middle East and North Africa. Washington DC, Population Reference Bureau, 2007.

8. AIDS epidemic update. Geneva, United Nations Joint Programme on HIV/AIDS, 2007.

9. Akala FA, El-Saharty S. Public health challenges in the Middle East and North Africa. Lancet, 2006, 367:961-964.
10. Yemen. HIV/AIDS treatment scale-up. Summary country profiles. World Health Organization, 2005 (http://www.who.int/hiv/ HIVCP_YEM.pdf, accessed 27 April 2010).

11. Towards universal access. Scaling up priority HIV/AIDS interventions in the health sector: progress report 2008. Geneva, World Health Organization, 2008.

12. Botswana: Champion of ART scale up in Africa. Country Stories Fact Sheet for Media. World Health Organization, 2006 (http://www.who.int/hiv/countrystories.pdf, accessed 27 April 2010).

13. AISerouri AW et al. Knowledge, attitudes and beliefs about HIV/AIDS in Sana'a, Yemen. Eastern Mediterranean Health Journal, 2002, 8:706-715.

14. Busulwa R et al. Perpcetions of the condoms as a method of HIV prevention in Yemen. Eastern Mediterranean Health Journal, 2006, 12:64-77.

15. Country profiles for population and reproductive health: policy developments and indicators 2005. New York, United Nations Population Fund and Population Reference Bureau, 2005.

16. Badahdah AM, Sayem N, Foote CE. Development of a Yemeni AIDS stigma scale. AIDS Care, 2009, 21:1-6.

17. Yemen: country profile. Overview of malaria control activities and programme progress. Geneva, World Health Organization, 
2005 (http://rbm.who.int/wmr2005/profiles/yemen.pdf, accessed 27 April 2010).

18. Madani T et al. Epidemiology of the human immunodeficiency virus in Saudi Arabia; 18-years surveillance results and prevention from an Islamic perspective. BMC Infectious Diseases, 2004, 4:1-8.

19. Ganczak M et al. Break the silence: HIV/AIDS knowledge, attitudes, and educational needs among Arab university students in United Arab Emirates. Journal of Adolescent Health, 2007, 40 : 572.e1-572.e8 (doi:10.1016/j.jadohealth.2007.01.0112).

20. Alrajhi A, Halim M, Al-Abdely H. Mode of transmission of HIV-1 in Saudi Arabia. AIDS, 2004, 18:1478-1480.

21. Kopelman LM. If HIV/AIDS is punishment, who is bad? Journal of Medicine and Philosophy, 2002, 27:231-243.
22. Ayranci U. AIDS knowledge and attitudes in a Turkish population: an epidemiological study. BMC Public Health, 2005, 13:1-10.

23. Montazeri A. AIDS knowledge and attitudes in Iran: results from a population-based survey in Tehran. Patient Education and Counseling, 2004, 57:199-203.

24. Tebourski F, Ben Alaya D. Knowledge and attitudes of high school students regarding HIV/AIDS in Tunisia: does more knowledge lead to more positive attitudes? Journal of Adolescent Health, 2004, 34:161-162.

25. Common misconceptions about HIV increase discrimination. Yemen Times, 12 August, 2009 (http://yementimes.com/article.shtml?i=1180\&p=health\&a=2, accessed 27 April 2010).

\section{International Conference on Opportunistic Pathogens, New Delhi, India, 27-30 September 2010}

Topics of concern and interest which will be addressed at the International Conference on Opportunistic Pathogens include: contracting opportunistic infections, resistance to anti-retroviral drugs, co-pathogens of HIV, receptor attachment, neuropathology, tissue tropism, testing guidelines, universal testing strategies, and future vaccine candidates against HIV.

Further information on the conference can be found at: http://icopa-india.org/defaulthtm 